\title{
A Research Framework for Engineering Location-Based Poetics
}

\author{
David E. Millard \\ Electronics and Computer Science \\ University of Southampton, UK \\ +44 (0)23 80595567 \\ dem@ecs.soton.ac.uk
}

\author{
Charlie Hargood \\ Electronics and Computer Science \\ University of Southampton, UK \\ +44 (0)23 80595749 \\ cah07r@ecs.soton.ac.uk
}

\begin{abstract}
Technology has always created new opportunities for storytelling, but in the last few decades the rate of change in technology has accelerated enormously, and our technological platforms have become fluid and uncertain. This is a problem because there is a relationship between the affordances and characteristics of the technology, and the poetics of our storytelling using that technology. In essence, different types of technology are good for telling different types of story in different ways, and yet technology is developed without any sense of its embedded poetics, and writers are left to experiment with the results. For example, location-based systems are now common, and there are many apps that experiment with location and storytelling, but the poetics of location-based narratives are poorly understood, and thus have not informed the development of those apps. In this paper we present a research framework, drawing on techniques from participatory design, UX, and Games Design, for exploring how writers can be involved in the process of building new software and as a result co-create both location-based technology and new location-based narrative forms.
\end{abstract}

\section{Categories and Subject Descriptors}

D.2.2 [Software Engineering] Design Tools and Techniques; H.5.2 [Information Systems] User Interfaces User-centered design

\section{General Terms}

Design, Human Factors, Theory,

\section{Keywords}

Location-Based Systems, Socio-Technical Design Methods

\section{INTRODUCTION}

Technology and storytelling have co-evolved over thousands of years and the narrative forms we are familiar with today are a result of this evolution. This has superficial effects (for example, the physical size of a codex has impacted the practical length of a novel) but also deeper poetic effects - encouraging particular types of story, and particular ways of writing.

Permission to make digital or hard copies of all or part of this work for personal or classroom use is granted without fee provided that copies are not made or distributed for profit or commercial advantage and that copies bear this notice and the full citation on the first page. Copyrights for components of this work owned by others than ACM must be honored. Abstracting with credit is permitted. To copy otherwise, or republish, to post on servers or to redistribute to lists, requires prior specific permission and/or a fee. Request permissions from

Permissions@acm.org.

$N H T^{\prime} 15$, September 1, 2015, Guzelyurt, TRNC, Cyprus.

(C) 2015 ACM. ISBN 978-1-4503-3797-7/15/09..\$15.00.

DOI: http://dx.doi.org/10.1145/2804565.2806671
Poetics is the theory of literature, and is typically applied to a wider variety of forms than just poetry. It is focused on how the parts of the text together create a reaction in the reader. In digital technology we see an explosion in the number of ways that a text can be formed (with a myriad of possible structural forms and media types), this enables wide experimentation, but has made the development of digital poetics challenging. Similarly, the lack of a strong critical sense of how digital stories are told has meant that new technology is developed without the benefits of this understanding. It makes digital storytelling an exciting and experimental area, but also means that it has been difficult to create general tools that are useable by a wide variety of authors.

In our work we are interested in exploring the poetics of location-based storytelling. There is a historical trend in the world of hypertext to identify patterns and create common models, at both the technical level and also in terms of the creative process [2]. These are founded on the critical theory of hypertext that seeks to understand how readers and authors negotiate meaning out of non-linear storytelling [18]. But as location-based systems are relatively new, the theoretical understanding of location-based narratives is still in its early stages; examples include attempts to categorise tour guides [17], to analyse the user experience of nonlinear situated narratives [3], and to explore the boundaries between storytelling and games [4]. Location aware narratives are poetically distinct from existing forms of narrative; due to their connection to location which itself may refer to the audiences context, a location within the narrative itself, or the context of the author. The impact on the narrative, and subsequently the poetics, can be via a number of mechanisms, including adaptation and interactivity.

In previous work we have highlighted the need to understand poetics in order to properly support emerging digital narrative forms [9], and have argued that this can best be achieved through an evolving and iterative approach that brings together software design, authoring and education.

In this position paper we explore how this might be achieved for location-based systems and stories as part of the engineering process. Our idea is to draw on participatory and co-design techniques, user experience (UX) design and Games design, and propose a research framework where this leads to practical deployments and critical evaluations of different fictional and non-fictional works.

\section{BACKGROUND}

There is an increasing prevalence of personal devices and apps with location awareness. These have emerged in diverse domains such as tour guides [5], located games [10], educational experiences [23] and interactive fiction [16]. As well as changing 
our experience of place, such systems have been demonstrated to alter our experience of narrative [15] offering exciting cultural potential. However, the vast majority of these tools are bespoke, taking custom approaches, deploying technology that is not reusable, and building creative skills that are not transferable. Therefore there is a real need to build a better theoretical understanding of what it means to construct location-based narratives and experiences, a poetics of location-based storytelling, which could then be embedded in improved tools, common models, and eventually standards.

Despite a history of experimental digital storytelling and critical analysis of digital stories (e.g. the classic Hypertext 'Afternoon' [22]) there is little understanding of how technology shapes, and could be shaped by, the narratives it carries. Partly this is due to the difficulties of interdisciplinary work between the Humanities and Computer Science and partly the lack of techniques available for Software Engineers. However, the last decade has seen Software Engineering start to explore nonfunctional applications more seriously, as represented by UserExperience (UX) research in areas such as ludic and emotional applications [11]. Substantial investment in interdisciplinary domains (such as the Digital Humanities and Web Science) has also begun to change the context of research. It is therefore an opportune time to explore the question of how critical literary theory can inform software design.

Location-based narratives are an ideal test-bed for this exploration. Location-based technology is now prevalent, and smart devices mean that our interaction with the Web and other forms of digital content now occur in a wide variety of locations and contexts. There is cultural and economic significance too, in that our storytelling culture is changing, with an increasing interest in transmedia storytelling [14], and a significant appetite for interactive storytelling (both online, and in the form of games). In both of these areas the lack of sophistication in narrative structure is a recognised problem [12], but there are no agreed solutions, and no clear understanding of how to develop new solutions.

The presence of potentially interactivity within location aware narrative raises further potential issues. Interactivity has previously been identified as potentially damaging to narrative cohesion, despite increasing audience immersion [1]. This impact of cohesion could potentially also affect the resulting poetics of a location aware narrative and further raises the question of whether an analysis of the experience of one individual is relevant to that of another.

\section{PROPOSED RESEARCH FRAMEWORK}

The proposed research framework consists of a significant co-design exercise based around multiple staggered locationbased story projects (shown in Figure 1, using three story projects as an example). Each story project is a separate activity with an independent location, and unique set of writers and stakeholders.

All three story projects will be developed through co-design, this is an established design process that seeks to draw all stakeholders equally into a mixed development team, blurring the lines between developer and client. In previous work we have developed a number of techniques for applying co-design to software creation in the mobile learning domain [20], and here we intend to develop these methods further, but in the creative space. Unlike traditional user-led design co-design makes no assumptions about the primacy of the user view, and is thus a good method for innovative applications, where technology changes practice rather then merely supporting and entrenching existing practice [19].

The co-design methodology we have previously established uses early brainstorming, prototyping, user-perspective modeling (such as storyboarding and scenarios), and iterative evaluation, to refine a design through a series of workshops and deployments. In this project we will augment this with the socio-cognitive approach proposed by [21]. Unlike similar participatory design methods this explicitly includes a theory-based study into the processes being discussed, and uses this to interpret the tasks being undertaken. This then functions as an analysis on not only what is done, but how people externalize their work (including their notes and diagrams, patterns of working, conventions and terminology). The socio-technical approach gives us the framework in which we can apply critical theory, and an avenue to turn those observations into design decisions, and ultimately new tools.

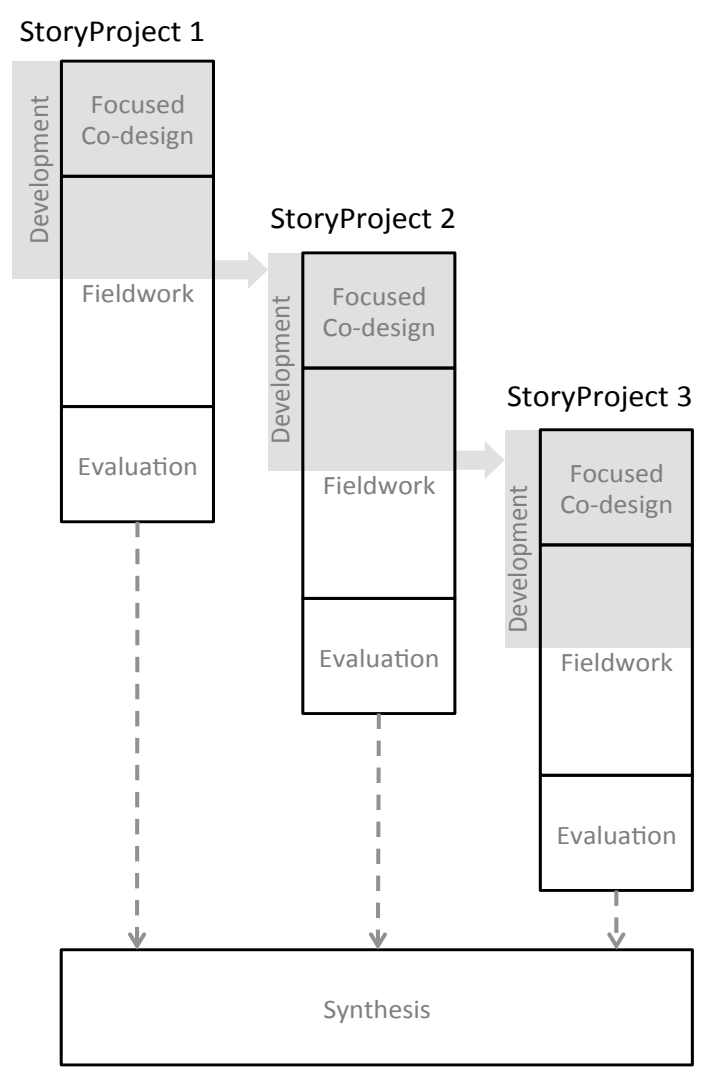

Figure 1: The Proposed Research Framework

Within these design sessions methods are required to allow the design team (which includes the wider stakeholders, including authors) to experiment with different structures, forms and presentations. Partly this can be achieved by rapid prototyping within each Story Project (where multiple iterations of software are brought back to design meetings for refinement), but we also propose to use Physical Prototyping, a technique used with games design [8], where paper and pen mockups are used to explore rules and structures. Physical Prototyping has the advantage of inclusivity, as even non-technical members of the design team can participate in high-level design decisions.

The story projects will be staggered to allow the design and development process to move from one story project to the next, 
with the expectation that the lessons learned (and technology developed) in one story project will become the starting point for the next.

Each project will have three distinct phases. The first phase will be the focused co-design activity using the methods described above, it will also give the writers time to research the space and develop narrative themes and ideas. The second phase will be fieldwork, an extended period in which writers use the tools that emerge from the co-design to create narrative works; development work will continue into the first half of this phase in order to support this activity. The third phase will be evaluation, this will involve public engagement with the work created, and evaluation of the experience (of both authors and readers).

Development should halt mid-way through the Fieldwork phase to allow a stable platform for writers to engage with to emerge. Development and design effort can then move to the next Story Project. The Fieldwork completes with a deployment, where the software is released with the example stories completed, and the final stage of Evaluation begins. This is where the poetics developed in the co-design is applied (in a critical way) and refined.

There are a number of techniques available to undertake this evaluation, including deep reading of the created works by critical experts, and ethnography of usage. However, we also expect to be able to use techniques from UX evaluation, including experience clips (short video clips provided by users that summarise their thoughts and feelings) [13], and experience deconstruction (a method for eliciting the specific properties values and effects of a given experience) [6].

At the end of the last Story Project the research enters a Synthesis stage in which the lessons across (what might be quite different) story projects are brought together. This final stage offers two important opportunities not available within the story projects themselves.

Firstly the experiences of both readers and writers across the story projects can be compared. This can be done through qualitative techniques such as semi-structured interviews of the authors, and focus groups of readers. UX techniques such as Repertory Grids may also provide insights into how working with different structures and approaches affects the experience of reading and writing location-based stories [7].

Secondly the co-design methodologies can be reflected on, and the design process compared with the outcomes. A case study format provides a good structure for recording the reflection, enabling factors that are unique to a particular story project to be included in the analysis.

The overall objective of this framework is to explore how emerging poetics can inform software engineering, specifically the design of innovative location-based software. In particular to answer the following research questions:

1) What are the poetics of location-based storytelling? Our assumption being that the character of place and affordances of the location-based technology (including the available adaptive structures and levels of interactivity) will shape narrative, and in turn that the narrative will shape the experience of place.

2) How can these poetics be reinforced/encouraged through software? Exploratory work in the story projects will transition into a more focused analysis of how narrative structures relate to the location-based technology, and which authoring processes are common or especially useful to authors. The staggered nature of the story projects means that the analysis of each story project can inform the technology development for the next project. In this way we hope to achieve the iterative evolution that we have previously identified as critical, developing tools that support the emerging poetics, encourage additional exploration, and in turn informing the next stage of co-design.

3) What are the processes/practices that enable critical theory to inform software design and engineering? Existing co-design methods will form a good basis to begin with, but by reflecting on the interactions between authors and developers, and on the way in which critical observations transform into new technology requirements, it should be possible to refine these methods for critical theory in the first story project, and in the second two story projects, develop and evaluate new co-design interaction methods.

\section{CONCLUSION}

Digital storytelling is increasingly diverse and important. Location-based narratives are a relatively new development and have huge cultural potential, but are only just beginning to be properly explored. This is because of the chaotic nature of app development, and a lack of theoretical understanding of what it means for digital narratives to be situated and contextual. In this position paper we have outlined a research framework to explore the poetics of location-based narratives, including the co-design and prototyping of authoring tools that embody those poetics and enable practical creative works to be developed and evaluations and analyses of those works to occur.

By bringing together computer scientists, hypertext theorists, and narrative and literary experts we can explore interdisciplinary ways of working together and building systems that lead to real innovation in both technology and the creative arts.

\section{ACKNOWLEDGMENTS}

Our thanks to the Leverhulme Trust, who have funded the StoryPlaces project to apply this framework to three story projects: The Bournemouth Natural Science Society, a substantial, towered Italian gothic Victorian house, that is part museum, part laboratory, part urban temple to learning; Crystal Palace Park a spectacular glass structure and its expansive grounds that stand as a landmark to Victorian grandeur and innovation, and speaks of panoramic horizons across the British Empire and wider globe; and Southampton - The City, the Port and the Sea, renowned as a port city, the home of great ocean liners, a place of arrival and departure, Southampton is a city whose own narrative is 'rooted in its waterway', historically offering a transient home to emigrants each of whom has a story to tell but seldom the chance to tell it.

\section{REFERENCES}

[1] Aylett. R. (1999) Narrative in virtual environments- towards emergent narrative. Technical report, Working notes of the Narrative Intelligence Symposium, 1999.

[2] Bernstein M. (1998) Patterns of hypertext. In ACM Hypertext '98.New York, NY, USA, 21-29.

[3] Blythe M., Reid J., Wright P., and Geelhoed E. (2006). Interdisciplinary criticism: analysing the experience of riot! a location-sensitive digital narrative. Behaviour \& Information Technology, 25(2):127-139 
[4] Bunting B., Hughes J., and Hetland T. (2012). The player as author: Exploring the effects of mobile gaming and the location-aware interface on storytelling. Future Internet, 4(1):142-160

[5] Davies, N., Cheverst, K., Mitchell, K., \& Efrat, A. (2001). Using and determining location in a context-sensitive tour guide. Computer, 34(8), 35-41

[6] Dix, A. 2003. Deconstructing Experience - pulling crackers apart. In: M. Blythe, K. O., A. F. Monk, P. C. Wright (eds.) Funology: From Usability to Enjoyment. Dordrecht, the Netherlands: Kluwer.

[7] Fallman, D., Waterworth, J. 2010. Capturing User Experiences of Mobile Information Technology with the Repertory Grid Technique. Human Technology, 6, 250-268.

[8] Fullerton, T. 2008. Game Design Workshop. A Playcentric Approach to Creating Innovative Games. $2^{\text {nd }}$ Edition Published by Elsevier, ISBN 978-0-240-80974-8.

[9] Hargood, C., Davies, R., Millard, D., Taylor, M. and Brooker, S. (2012) Exploring (the poetics of) strange (and fractal) hypertexts. In ACM Hypertext 2012, New York, NY, USA,

[10] Herbst, I., Braun, A.-K., McCall, R., \& Broll, W. (2008). TimeWarp: interactive time travel with a mobile mixed reality game. Presented at the ACM Conference on MobileHCI '08

[11] Gaver, B. (2009). Designing for Homo Ludens, Still. In (Re)searching the Digital Bauhaus, Binder, T., Löwgren, J., and Malmborg, L. (eds) London: Springer, 163-178.

[12] Horswill, I. D., Montfort, N., \& Young, R. M. (2014). Guest Editorial: Computational Narrative and Games. IEEE Transactions on Computational Intelligence and $\mathrm{AI}$ in Games, 6(2), 93-96.

[13] Isomursu, M., Tahti, M., Vainamo, S., Kuutti, K. 2007. Experimental evaluation of five methods for collecting emotions in field settings with mobile applications. International Journal of Human-Computer Studies, 65, 404418
[14] Jenkins, H (2003). Transmedia Storytelling. Technology Review, MIT

[15] Karapanos E., Barreto M., Nisi V., and Niforatos E. (2012), Does locality make a difference? Assessing the effectiveness of location-aware narratives. Interacting with Computers, 24(4):273-279, July.

[16] Khaled, R., Barr, P., Greenspan, B., Biddle, R., \& Vist, E. (2011). StoryTrek: experiencing stories in the real world. Presented at the MindTrek '11: Proceedings of the 15th International Academic MindTrek Conference: Envisioning Future Media Environments

[17] Kjeldskov J. and Paay J. (2007) Augmenting the city with fiction: fictional requirements for mobile guides. Mobile Interaction with the Real World, pages 41-45.

[18] Landow, G. P. (1994) 'What's a Critic to Do?: Critical Theory in the Age of Hypertext' in Hyper/text/theory (ed. George Landow) Baltimore: John Hopkins University Press

[19] Millard, David E., Borthwick, Kate, Howard, Yvonne, McSweeney, Patrick and Hargood, Charlie (2013) The HumBox: changing educational practice around a learning resource repository. Computers \& Education, 69, 287-302.

[20] Millard, D., Howard, Y. Gilbert, L. and Wills, G. (2009) Codesign and Co-deployment Methodologies for Innovative mLearning Systems. In, Multiplatform E-Learning Systems and Technologies: Mobile Devices for Ubiquitous ICTBased Education. IGI Global.

[21] Sharples M., Jeffery N., du Boulay J. B. H., Teather D., Teather B. and du Boulay G. H. (2002) Socio-cognitive engineering: A methodology for the design of human-centred technology, European Journal of Operational Research Vol. 136, No 2, Jan 2002, Pages 310-323,

[22] Walker, J. (1999). Piecing Together and Tearing Apart: Finding the Story in Afternoon. ACM Hypertext ' $99,111-$ 117.

[23] Weal, Mark J., Cruickshank, Don G., Michaelides, Danius T., Millard, David E., De Roure, David C., Halloran, John, Hornecker, Eva and Fitzpatrick, Geraldine (2006) A persistent infrastructure for augmented field trips. In EdMedia 06, Orlando, Florida, USA 